\title{
Range Shifts of Overwintering Birds Depend on Habitat Type, Snow Conditions and Habitat Specialization
}

Laura Bosco ( $\square$ laura.bosco@helsinki.fi )

Finnish Museum of Natural History: Luonnontieteellinen museo https://orcid.org/0000-0001-66162641

\section{Yanjie Xu}

Finnish Museum of Natural History: Luonnontieteellinen museo

\section{Purabi Deshpande}

Finnish Museum of Natural History: Luonnontieteellinen museo

\section{Aleksi Lehikoinen}

Finnish Museum of Natural History: Luonnontieteellinen museo

\section{Research Article}

Keywords: Distribution shifts, global warming, habitat use, bird monitoring, climate niche

Posted Date: January 5th, 2022

DOI: https://doi.org/10.21203/rs.3.rs-1170896/v1

License: (c) (i) This work is licensed under a Creative Commons Attribution 4.0 International License. Read Full License 


\section{Abstract}

Climatic warming is forcing numerous species to shift their ranges poleward, which has been demonstrated for many taxa across the globe. Yet, the influence of habitat types on within- and amongspecies variations of distribution shifts has rarely been studied, especially so for the non-breeding season. Here, we investigated habitat specific shift distances of northern range margins and directions of the center of gravity based on a long-term dataset of overwintering birds in Finland. Specifically, we explored influences of habitat type, snow cover depths, species' climatic niche and habitat specialization on range shifts from 1980's to 2010's in 81 bird species. Birds overwintering in farmlands shifted significantly more often northwards than birds of the same species in rural and forest habitats, while the northern range margin shift distances did not significantly differ among the habitat types. Snow cover was negatively associated with the eastward shift direction across all habitats, while we found habitat specific relations to snow cover with northward shift directions and northern range margins shift distances. Species with stronger habitat specializations shifted more strongly towards north as compared to generalist species, whereas the climatic niche of bird species only marginally correlated with range shifts, so that cold-dwelling species shifted longer distances and more clearly eastwards. Our study reveals habitat specific patterns linked to snow conditions for overwintering boreal birds and highlights importance of habitat availability and preference in climate driven range shifts.

\section{Introduction}

Anthropogenic climate change is widely recognized as a major threat to global biodiversity (Thomas and Williamson 2012), exacerbating the sixth mass extinction in the history of our planet (Bellard et al. 2012). Numerous ecosystems are at risk of severe impacts globally, while arctic ecosystems are particularly vulnerable (Masson-Delmotte et al. 2018). It is thus crucial to understand how communities respond and adapt to the spatiotemporal variability in their environment, making it a key research area in ecology (Begon et al. 1986). To design effective conservation and management strategies and mitigation measures to climate change, we need a holistic understanding of the ecological, physiological, genetic, and biogeographical mechanisms driving species responses to climate change (Bonebrake et al. 2018). Current climate change scenarios are further predicting a significant increase in global mean temperatures above pre-industrial levels (Masson-Delmotte et al. 2018). However, ongoing responses to climate change are already visible among many taxa, where a growing body of research has shown that species respond to climate-driven changes in their climatic niche in multiple ways (Both et al. 2006; Chen et al. 2011; Bellard et al. 2012; Stephens et al. 2016; Ryding et al. 2021).

Changes in the distribution of species linked with climatic conditions are well researched. A clear consensus exists that in general species are shifting poleward (Devictor et al. 2008; Mason et al. 2015; Lehikoinen and Virkkala 2016), however the velocity of these shifts differs between different taxa (e.g., butterflies shift faster than birds, Devictor et al. 2012). There are also variations in poleward shifts between different biogeographical populations within similar taxa, where northern boreal species shift faster than southern species (Virkkala and Lehikoinen 2014) and can be facilitated by increased habitat 
quality including protected areas (Lehikoinen et al. 2019). Moreover, species responses to climate change are modified through their habitat use. For instance, species-specific variation in poleward shifts of invertebrates in the UK can be explained by habitat availability (Platts et al. 2019), and the rapid northward expansion of wintering birds in the UK is linked to resource availability related to humanmodified landscapes (Van Doren et al. 2021). Also, in the case of Finnish butterflies, habitat availability plays a crucial role in whether a species can expand its range poleward or not (Pöyry et al. 2009). Other research revealed that odonates specialized to lentic habitats have shifted their home ranges poleward faster than those adapted to lotic habitats (Grewe et al. 2013), or that bird species breeding in scrub and grassland habitats show substantial poleward shifts, while urban, wetland and woodland-breeding species show a non-significant poleward shift (Hovick et al. 2016).

The range shifts can be influenced by changes in climatic conditions during both breeding and wintering seasons. Winter conditions vary geographically more than summer conditions (Bonan et al. 2003) and hence it is crucial to understand how species are moving poleward due to winter conditions rather than the warmer season solely (Lehikoinen et al. 2021). Overwintering is a key component of the biology of organisms that live in temperate, polar, and alpine habitats, and has driven the evolution of extreme phenotypes such as dormancy and migration (Williams et al. 2015). Habitat use can influence how climatic conditions during winter affect distribution changes in both aquatic and terrestrial ecosystems. For instance, diving ducks which are foraging in open water areas have shifted their wintering sites more rapidly than other waterbird species, which are foraging on coastal areas or farmlands (Pavón-Jordán et al. 2019). Land birds on the other hand can be attracted to human settlements, where access to food is easier during harsh winter conditions (Goławski and Kasprzykowski 2010), whereas in milder conditions birds are more evenly distributed or even aggregated in rural areas (Deshpande et al. 2021). The primary abiotic drivers of the biological impacts of winter conditions on terrestrial systems are temperature and snow cover (Williams et al. 2015), which are often highly correlated (Deshpande et al. 2021). Yet, the interaction between habitat use and varying snow or temperature conditions on range shifts of species have only weakly been investigated so far.

In this study, we aimed to understand how habitat type influences intra-specific range shift of species during winter season, measured as changes in their central gravity of abundance and northern range margin over time. Using long-term winter bird monitoring data covering 81 species from Finland, we sought to answer the following questions: (i) do abundances and range margins of species shift differently dependent on the habitat type they overwinter in, (ii) is this difference influenced by the their overwintering thermal preference (measured by Species Temperature Index STI, e.g. (Devictor et al. 2008; Santangeli and Lehikoinen 2017) of species, (iii) is snow cover influencing the different abundance and range margin shifts per habitat type, and (iv) do species shift faster in their preferred (main) habitat compared to other (sub) habitats and is the speed of the shift dependent on how specialized the species is to the preferred habitat.

First, we hypothesize that overwintering birds shift faster north and eastwards in farmlands because in open farmlands the decrease in snow cover (due to climate change) can significantly increase the 
accessibility of species to food resources (Henderson et al. 2004; Goławski and Kasprzykowski 2010). Alternatively, the shifts could be faster in rural and urban areas, where e.g., supplementary feeding by humans can provide improved food resources as compared to situations in farmlands and forests (Fraixedas et al. 2015). Second, we also hypothesized that cold-dwelling (lower STI) species would shift faster than warm-dwelling (higher STI) species as similar results have been found during the breeding season (Virkkala and Lehikoinen 2014, Tayleur et al. 2016). Third, we predicted that reduced snow conditions would favor faster shifts towards north and east in all habitats, but that the impact could be stronger in farmland habitats especially compared to rural and urban areas where supplementary feeding will provide food for birds at lower latitudes. Fourth, we hypothesized that species would move faster inside their main habitat type compared to sub habitats and species which have higher specialization to its main preferred habitat would move faster than generalist species.

\section{Methods}

\section{Winter bird counts and data selection}

We used a long-term dataset consisting of bird observations based on the winter bird counts from Finland starting in the early 1950s (Koskimies and Väisänen 1991). Since the 1970s the counts have consisted of a three-visit survey between November and March, wherein volunteers count all birds encountered on a transect band (of on average $10 \mathrm{~km}$ long). In each survey, trained observers walk along the predefined route and count all birds detected. Among a total of $>76,000$ winter bird surveys from $>4,100$ transects, we restricted our analyses to two time periods, with period one including the years 1987-2000 and period two 2010-2020 (hereafter period 1 and 2, respectively), where the habitat data had been collected from the transects. We further only selected the mid-winter counts between 25 December and 7 January, as this period had the highest number of surveys (see Lehikoinen et al. 2013; Fraixedas et al. 2015). Next, we excluded surveys where information on the habitat type was missing, so that our final dataset had information on the habitat type per transect segment length and bird observations. The original classification from the winter bird survey protocol distinguishes between eight habitat types (dump, urban, countryside, field, forest, other, clear-cut, reed and shoreline vegetation), while we summarized them to four classes for the purpose of this study: urban (dump + urban), rural (countryside), farmland (field), and forest (forest + clear-cut + reed). Observations from the class "other" were dropped from our dataset, which consisted of a total of $63^{\prime} 249 \mathrm{~km}$ of transects during period 1 (ESM Fig. S1; 13'680 km, 13'027 km, 9'706 km, and 26'837 km in urban, rural, farmland, and forest habitats, respectively), while $57^{\prime} 503 \mathrm{~km}$ of transects were surveyed during period 2 (ESM Fig. S1; 15'934 $\mathrm{km}, 10^{\prime} 778 \mathrm{~km}, 7^{\prime} 086 \mathrm{~km}$, and 23'704 km in urban, rural, farmland, and forest habitats, respectively). We generated $100 \times 100 \mathrm{~km}$ grids covering the extent of Finland and assigned each transect to the grid that contained the geometric center of the transect (ESM Fig. S1). We calculated the habitat-specific sum of transect lengths in each grid per period and included those grids with a total of $>1 \mathrm{~km}$ of transects surveyed per habitat type in the subsequent analysis. To reduce the potential bias from counting rare species, we only included species with $\geq 10$ individuals observed per habitat type and period and $\geq 40$ 
individuals observed per habitat type in both periods together, which resulted in a total of 81 bird species that were included.

\section{Species range shift}

To quantify the direction and magnitude of range shifts of wintering birds in Finland, we calculated the central gravity of species density and northern range margins of their distributions in periods 1 and 2 . The species densities $(\mathrm{n} / \mathrm{km}$ ) (hereafter densities) were calculated separately for each 100-km grid per habitat and period, by dividing total abundances of each species per habitat type by the total surveyed transect length $(\mathrm{km})$. We used these grid-specific densities to calculate arithmetic central gravity of densities for each species per habitat and period. This was performed by first calculating the latitude using mean densities per each latitude grid row and then calculating the longitude using mean densities per each grid column (Virkkala and Lehikoinen 2014). Since the central gravity of densities was affected by the location of transects inside each grid, the mean of coordinates of all transects per grid per period was used, instead of the grids' geographic centroids (after Lehikoinen and Virkkala 2016). Based on latitude and longitude of the centers of gravity per period, we calculated the distance and geographic direction of the density shift per species between the two periods for each of the four habitat types separately. We further calculated the northern range margins by averaging the latitudes of the three northernmost grids per habitat, period, and species. Thus, shifted distances in northern range margins were quantified by their differences between the two periods, whereby we excluded those species-habitat observations where the habitat-specific northern margin was farther north than $66.85^{\circ} \mathrm{N}$. Hence, only observations where the species had space to shift northward were included in this analysis (i.e., 4 species and 54 observations were excluded, resulting in 77 species and 180 observations in the dataset). We did not include southern range margin shifts since very few species in the dataset would have their trailing edge within Finland, which was reflected in no detectable shift in the southern margin in our data (ESM Fig. S4b).

\section{Species habitat specificity}

To test whether species shift differently in the main overwintering habitat with highest species-specific densities (main habitat) compared to other used habitats (sub), we used winter bird counts from a period in between our two study periods, i.e., years 2000-2009, as sort of an independent dataset from our study data but nevertheless representative for the habitat-specific overwintering behavior of Finnish birds. We applied the same habitat classification steps as described above and then calculated species densities per habitat type for the 81 bird species included in our study. The habitat type with highest absolute density was subsequently classified as 'main', while the remaining habitats were classified as 'sub'. We also quantified species habitat specialization by calculating their habitat-specific densities (absolutedensityperhabitat/ totaldensityoverallhabitats), and used this continuous variable (habitat-specific density per species) in the modeling.

\section{Explanatory variables}

We downloaded gridded daily snow cover data for the time between 24 December and 7 January from the Finnish Meteorological Institute (https://en.ilmatieteenlaitos.fi/download-observations) at a $10 \mathrm{~km} \mathrm{x}$ 
$10 \mathrm{~km}$ resolution and averaged per year in period one and two. We then calculated the mean snow cover per period in the original data resolution $(10 \mathrm{~km})$ and extracted the values to the transect coordinates. To match our final bird range shift data, we next summarized the median snow cover per 100-km grid from all transects present in each grid. For the modeling, we finally extracted the habitat-specific median snow cover from period two, only from the grids where the species was present in period one in the respective habitat type.

To model the influence of species' thermal preferences and influence of their latitudinal distribution thereof, we included the winter-specific Species Temperature Index (STl; available at Lehikoinen et al. 2021) of each species present in the dataset.

\section{Statistical analyses}

We ran separate analyses for the response variables i) direction (eastward and northward, see below) of central gravity shifts, and ii) shift distance of northern range margins in each habitat, while always testing the same set of predictors in all models. To model circular data such as compass direction of range shifts with linear regression models, we transformed the shift direction to a linear expression of northward (shift along the latitudinal axis) and eastward (longitudinal axis) shift (sensu Guyot et al. 2017). To do so, we first transformed directions from degrees to radians (direction / $360 * 2 * \pi$ ) and then calculated the sine and cosine for a measure of eastward (ranging from $-1=$ west, to $+1=$ east) and northward ( $-1=$ south, $+1=$ north) directions respectively. Consequently, we modeled eastward and northward range shifts separately, following the same statistical protocol by fitting mixed effect linear regression models ('Imer', R package 'Ime4', Bates et al. 2015). The range shift distance of the central gravity was added as a weight in all eastward and northward direction models to account for the notable variation in distance among the range shifts (Fig. 1), and the factor species was always included as a random effect (81 levels).

For distance of northern range margin shifts, we also fitted Imer models and always included the factor species (77 levels) as a random effect to account for varying intercepts among species. To test the first three hypotheses, we ran the following models for all response variables $(\mathrm{p} 2=$ period 2$)$ :

$\mathrm{m} 1: \mathrm{y} \sim$ habitat

m2: y habitat + STI

m3: y habitat ${ }^{\star}$ STI

m4: $y \sim$ habitat + snow p2

m5: y habitat*snow p2

To test range shift differences in main vs. sub habitats, we reduced the dataset to those species with occurrences in $>2$ habitat types, by dropping 15 species with only one habitat type (66 species left, see ESM table S5). From there, we tested differences in habitat specific shifts of northern range margins, and 
eastward and northward shift directions as a function of main vs. sub habitat type classification using linear mixed models (gaussian error distribution) with species as random factor.

To test range shift differences among specialists $v s$. generalists, we used the relative densities as a proxy for habitat specialization and reduced the dataset to unique species observations, such that per species only the range shift information (i.e., shift distance of northern margin, eastward and northward shift direction) of their main overwintering habitat (habitat $=$ main) was retained (i.e., 80 observations from 80 species, as one species had no main habitat in our dataset). We then again modelled northern range margin shift distance, eastward and northward shift directions against the relative densities using linear regression models.

Finally, linear regressions of model predictions were plotted for variables with significant effects by absorbing the term of interest, and averaging over other terms in the model, if there were any present (function 'effect' in the R package 'effects', Fox \& Weisberg 2019). For all data processing and statistical analyses, we used $R$ software ( $R$ version 4.0.3 2020-10-10, R Core Team 2020).

\section{Results}

Shift distances of northern margins were quite equally distributed along the latitudinal axis, with distances ranging from $0-413.75 \mathrm{~km}$ (mean $\pm S D=111.06 \pm 92.09 \mathrm{~km}$ ) towards north and $0-523.33 \mathrm{~km}$ $(90.74 \pm 100.51 \mathrm{~km})$ towards south (ESM Fig. S3). In general species were shifting northwards in their northern range margins in all four habitat types (i.e., positive latitudinal distance values), but there were no significant differences between habitat types $( \pm S D)$ rural $(46 \pm 139 \mathrm{~km} \mathrm{SD})$, urban (44 $\pm 125 \mathrm{~km})$, farmland $(37 \pm 134 \mathrm{~km})$ and forest $(35 \pm 147 \mathrm{~km})$.

There was considerable variation in the direction of central gravity shifts among the four habitat types (Fig. 1), where birds mainly shifted northwards in farmlands (Fig. 1a). Shifts in forest habitats were mainly towards the northeast (Fig. 1C), whereas most distances of these shifts are less than $150 \mathrm{~km}$ (Fig. 1d). In contrast, birds in rural and urban habitats showed density shifts, especially towards west and south directions, respectively (Fig. 1c, d).

\section{Central gravity shift directions}

Eastward shift - The top ranked model explaining eastward shifts in center of gravity included snow cover depth as a main explanatory variable ( $\mathrm{m} 4$ : habitat and snow p2, Table 1$)$. Species across all habitats tended to move eastwards with decreasing snow depths in the second period (Table 1, ESM Table S1, Fig. S6). 
Table 1

Model outputs (estimates, standard errors SE, $t$ and $p$ values) for the top models for direction of central gravity shifts, separately for eastward ( $\mathrm{m} 4$ ) and northward ( $\mathrm{m} 5$ and $\mathrm{m} 2$ ) shift directions, and northern range margin shift distances (m5). Significant and marginal effects $(p<0.1)$ are depicted in bold. Continuous predictors were standardized prior to modeling. For the factor habitat, farmland was used as reference level in all models. All other models are shown in ESM Tables S1 and S2.

\begin{tabular}{|lcccc|}
\hline Term & Estimate & SE & t-value & p-value \\
\hline Shift direction: Eastward $(m 4)$ AlC & 535.004 & & \\
\hline Intercept & -0.065 & 0.103 & -0.626 & 0.532 \\
\hline Habitat forest & 0.179 & 0.120 & 1.491 & 0.137 \\
\hline Habitat rural & 0.133 & 0.121 & 1.099 & 0.273 \\
\hline Habitat urban & 0.003 & 0.116 & 0.029 & 0.977 \\
\hline Snow period 2 & -0.135 & 0.053 & -2.538 & 0.012 \\
\hline Shift direction: Northward $(m 5)$ AlC $=550.240$ & & \\
\hline Intercept & 0.065 & 0.167 & 0.389 & 0.697 \\
\hline Habitat forest & -0.066 & 0.175 & -0.377 & 0.707 \\
\hline Habitat rural & -0.073 & 0.178 & -0.410 & 0.683 \\
\hline Habitat urban & 0.043 & 0.176 & 0.245 & 0.807 \\
\hline Snow period 2 & -0.298 & 0.216 & -1.384 & 0.168 \\
\hline Snow period 2:Forest & 0.442 & 0.222 & 1.994 & 0.047 \\
\hline Snow period 2:Rural & 0.482 & 0.221 & 2.184 & 0.030 \\
\hline Snow period 2:Urban & 0.268 & 0.227 & 1.181 & 0.239 \\
\hline Shift direction: Northward $(m 4)$ AlC $=550.815$ & & \\
\hline Intercept & 0.330 & 0.108 & 3.057 & 0.003 \\
\hline Habitat forest & -0.321 & 0.122 & -2.623 & 0.009 \\
\hline Habitat rural & -0.325 & 0.124 & -2.611 & 0.010 \\
\hline Habitat urban & -0.198 & 0.119 & -1.670 & 0.096 \\
\hline Snow period 2 & 0.116 & 0.056 & 2.065 & 0.040 \\
\hline Northern margin distance $(m 5)$ AlC $=2304.578$ & \\
\hline Intercept & 94.160 & 39.070 & 2.410 & 0.017 \\
\hline
\end{tabular}




\begin{tabular}{|lllll|}
\hline Term & Estimate & SE & t-value & p-value \\
\hline Snow period 2 & -12.162 & 6.363 & -1.911 & 0.058 \\
\hline Habitat forest & 28.715 & 48.209 & 0.596 & 0.552 \\
\hline Habitat rural & -76.927 & 48.674 & -1.580 & 0.116 \\
\hline Habitat urban & -0.231 & 52.343 & -0.004 & 0.996 \\
\hline Snow period 2:Forest & 0.789 & 7.515 & 0.105 & 0.916 \\
\hline Snow period 2:Rural & 14.557 & 7.211 & 2.019 & $\mathbf{0 . 0 4 5}$ \\
\hline Snow period 2:Urban & 5.857 & 8.413 & 0.696 & 0.487 \\
\hline
\end{tabular}

Northward shift - The two top ranked models explaining northward shifts in center of gravity had very similar AIC values (Table 1) and are thus both presented ( $\mathrm{m} 4$ and $\mathrm{m} 5$ ). Model 4 (habitat and snow p2) demonstrated that populations overwintering in farmlands have significantly shifted northwards, while forest and rural species show no clear shift pattern along the latitudinal axis (Fig. 2, Table 1). The significant positive influence of snow depth in period 2 (Table 1) indicates that the more snow in period 2, the faster the species shifted northwards overall (ESM Fig. S8). Yet in model 5 (habitat * snow p2) we demonstrate that the influence of snow on the northward shift direction depends on the habitat type based on a significant interaction of habitat with snow depth in period 2. This interaction shows that rural and forest species had a significantly different slope from farmland species, with the latter being negatively related to snow depth while forest and rural habitats showed a slight positive trajectory with snow depth (ESM Fig. S9). This means that in farmlands, with lower snow cover depths, species move northwards compared to forests and rural areas.

\section{Northern range margin shift distances}

The top performing model was the interaction model habitat * snow (m5) (Table 1). Snow depth in period 2 had an overall marginal negative connection to shift distance in the northern range margin meaning that with lower snow depth in period 2 species shifted their range margins further north across all habitat types (Table 1, Fig. 3a-d, ESM Fig. S10). However, according to the significant positive interaction between snow depth and rural habitat compared to farmland and forest habitats (Table 1; Fig. 3a, b), snow conditions did not have a major correlation in range margin shifts in rural habitats (Fig. 3c) while there was a clear negative relation in farmland and forest habitats. STI was not selected to the top model and thus had no connection on northern margin shift distances (Table 1, ESM Table S2).

\section{Shift differences among main vs. sub habitats and generalist vs. specialist bird species}

Main Habitat - We found no difference in shift distance of northern range margins or northward shift in center of gravity between main and sub habitats (ESM Table S3). However, there was a tendency that 
species' center of gravity shifted less clearly eastwards in their main habitats compared to the sub habitats $(b=-0.160 \pm 0.087 \mathrm{SE}, t=-1.849, p=0.066$, ESM Fig. S11), so that.

Specialization - Specialists shifted their center of gravity towards north more significantly than generalists inside their main habitat type ( $b=0.290 \pm 0.114 \mathrm{SE}, t=2.549, p=0.013$, Fig. 4). However, there was no apparent difference among generalists $v s$. specialists regarding their northern margin shift distance and eastward shift direction (ESM Table S3).

\section{Discussion}

There is ample evidence demonstrating the significant impacts of climate change on species' distributions across the globe, including different taxa, ecosystems, and climatic regions (e.g., Hickling et al. 2006; Mason et al. 2015). Yet how these distribution shifts may differ among different habitat types not only among but also within species - has rarely been studied before. Here, we tested the long-term influences of habitat type, winter weather conditions measured as snow cover depths and species climatic niches measured as STI, on overwintering bird range shifts across Finland. In summary, our findings based on long-term observations of overwintering bird abundance and distribution emphasize the role of habitat use in climate-driven range shifts, as habitat type, snow cover, and species habitat specialization all affect the pattern of species range shifts in winter.

We show that the northward shift direction of the center of gravity was stronger in farmland compared to forest and rural habitats - which partly supports our hypotheses in the first study question. As expected, the snow conditions had an important connection with shifts of both range margin distances (marginally negative) and directions in center of gravity (negative for eastward and positive for northward directions), while the strength and sign of the relationship was strongly dependent on the habitat type; reduced snow cover tended to enhance shifts towards north in farmlands and forests compared to rural habitats. The climatic niche (STI) of species had weak connections on species shifts. We did not find any support that species would move faster in their main preferred habitat compared to sub habitats but demonstrate that habitat specialist species showed stronger shifts towards north compared to generalist species. Our results underline that habitat and climate interactively drive species range shifts, and thus seasonspecific habitat factors should be considered when studying climate-driven range shifts.

Species using different habitats may shift differently throughout their annual cycle, as habitat type also partly explains the variation in the directional pattern of range shifts in breeding birds (Lehikoinen and Virkkala 2016). However, habitats and their climatic conditions may play a more important role in winter because of the unique constraints for overwintering species, through e.g., snow cover and scarcity in food resources. Also, species tend to show lower site-fidelity in winter and could thus shift their distributions faster compared to the breeding season - as shown e.g., for European and North American winter bird communities that have been changing faster towards a dominance of warm-dwelling species than breeding communities (Lehikoinen et al. 2021). However, we failed to detect strong relationships between species' climatic niche (i.e., STI) and range shift patterns of Finnish overwintering birds, which could 
indicate that community compositions are changing due to both contractions of cold-dwelling species and expansions of warm-dwelling species.

We show that birds overwintering in farmlands shift northwards faster than those overwintering in forest and rural areas, by a more directional northward abundance shift and further distances in their northern range margins. In addition, farmland and forest birds showed a negative connection to snow depths as compared to rural birds in their northern range margin shift distances. This may be explained by the increasing accessibility to wintering food resources for farmland birds because of stronger effect of snow cover loss with climatic warming in open lands (Goławski and Kasprzykowski 2010). Food scarcity in winter may be one of the key forces for climate-driven range shifts, whereas supplementary food resources provided by humans, such as garden feeders (Van Doren et al. 2021), may facilitate overwintering birds to cope with changing climates without having to shift their range. Thus, birds wintering in rural (and urban) habitats, with a higher proximity to human settlements, shifted less clearly northwards as compared to farmland birds. We also found that shifts in forests were less directionally northwards than in farmland. In contrast, density shifts towards northern directions have been faster in breeding forest bird species compared to farmland species (Virkkala and Rajasärkkä 2011; Lehikoinen and Virkkala 2016). This implies different underlying mechanisms for overwintering vs. breeding birds' range shifts, which - as partly demonstrated here - may be linked to winter snow cover and food resources.

Our results provide novel insights for the important role of snow cover and habitat type in range shifts of boreal wintering birds. In Finland, the abundances of overwintering birds have been shown to vary with habitat type and snow depths, with abundances of birds in rural and farmland areas increasing with a decrease in snow depth (Deshpande et al. 2021). The results of our study further explain how such an increase in abundance could be driven by poleward shifts in the distribution of these species. We identified significant effects of its main or interaction terms in all the top models, while its effects overall were stronger (and negative) for farmland birds. A decreasing snow depth significantly facilitates species' eastward shift, which indicates that the loss of snow cover under climatic warming may promote species to move towards pole directions.

We further observed a more directional northward shift in habitat specialists than generalists, indicating that species with less flexibility in using different habitats may respond to climatic warming more strongly by shifting their wintering ranges towards North. However, we failed to find clear evidence supporting within-species variations of poleward shifts between their main and sub habitats. There is a growing body of evidence showing that species traits explain the variation in their response to climate change (MacLean and Beissinger 2017; Pacifici et al. 2017), to which this study contributes, and we thus suggest taking habitat-relevant traits into account. Species traits that related to habitat use could indirectly shape the pattern of range shifts by interactions between climate and land cover changes, such that neotropical and temperate migratory birds showed contrasting range shift patterns (Rushing et al. 2020). Such traits also affect the abundance trends of birds. Migratory distance and the size of the nonbreeding grounds explain population trends of migratory birds, as they are relevant to the birds' exposure 
to habitat loss and climate change (Patchett et al. 2018). Our study shows that species habitat use can affect the speed of range shifts during the non-breeding season, highlighting that to understand how climate change affects species' populations, the impacts should be studied throughout the species' annual cycle including potential carry over and habitat-specific effects.

\section{Declarations}

Acknowledgements: We thank the many volunteers conducting winter bird monitoring over the past 50 years in Finland, and all who handled and provided the data.

Funding: This study was supported by the Academy of Finland (grants 323527 \& 329251) and the Swiss National Science Foundation (grant P2BEP3_195232). PD is supported by the Kone Foundation (grant 201904974). The Finnish Ministry of the Environment has supported winter bird counts.

Conflict of Interest: The authors declare that they have no conflict of interest.

Ethical approval: All applicable institutional and/or national guidelines for the care and use of animals were followed.

Availability of data and material: The data will be deposited in an online repository.

Code availability: The code will be deposited in an online repository.

Author Contributions: AL, YX, PD and BL originally formulated the idea, $A L, Y X$ and $L B$ developed methodology, $Y X$ and LB performed statistical analyses, and $Y X, L B, P D$ and $A L$ wrote the manuscript.

\section{References}

1. Bates D, Mächler M, Bolker B, Walker S (2015) Fitting Linear Mixed-Effects Models Using Ime4. J Stat Softw 67. https://doi.org/10.18637/jss.v067.i01

2. Begon M, Harper JL, Townsend CR (1986) Ecology. Individuals, populations and communities. Blackwell scientific publications

3. Bellard C, Bertelsmeier C, Leadley P et al (2012) Impacts of climate change on the future of biodiversity. Ecol Lett 15:365-377. https://doi.org/10.1111/j.1461-0248.2011.01736.x

4. Bonan GB, Levis S, Sitch S et al (2003) A dynamic global vegetation model for use with climate models: concepts and description of simulated vegetation dynamics. Glob Chang Biol 9:1543-1566. https://doi.org/10.1046/j.1365-2486.2003.00681.x

5. Bonebrake TC, Brown CJ, Bell JD et al (2018) Managing consequences of climate-driven species redistribution requires integration of ecology, conservation and social science. Biol Rev 93:284-305. https://doi.org/10.1111/brv.12344

6. Both C, Bouwhuis S, Lessells CM, Visser ME (2006) Climate change and population declines in a long-distance migratory bird. Nature 441:81-83. https://doi.org/10.1038/nature04539 
7. Chen IC, Hill JK, Ohlemüller R et al (2011) Rapid range shifts of species associated with high levels of climate warming. Science (80-) 333:1024-1026. https://doi.org/10.1126/science.1206432

8. Deshpande P, Lehikoinen P, Thorogood R, Lehikoinen A (2021) Snow depth drives movement of birds between urban, rural and forest habitats. Under Revision

9. Devictor V, Julliard R, Couvet D, Jiguet $F$ (2008) Birds are tracking climate warming, but not fast enough. Proc R Soc B Biol Sci 275:2743-2748. https://doi.org/10.1098/rspb.2008.0878

10. Devictor V, Van Swaay C, Brereton T et al (2012) Differences in the climatic debts of birds and butterflies at a continental scale. Nat Clim Chang 2:121-124. https://doi.org/10.1038/nclimate1347

11. Fraixedas S, Lehikoinen A, Lindén A (2015) Impacts of climate and land-use change on wintering bird populations in Finland. J Avian Biol 46:63-72. https://doi.org/10.1111/jav.00441

12. Goławski A, Kasprzykowski Z (2010) The influence of weather on birds wintering in the farmlands of eastern Poland. Ornis Fenn 87:153-159

13. Grewe Y, Hof C, Dehling DM et al (2013) Recent range shifts of European dragonflies provide support for an inverse relationship between habitat predictability and dispersal. Glob Ecol Biogeogr 22:403409. https://doi.org/10.1111/geb.12004

14. Guyot C, Arlettaz R, Korner P, Jacot A (2017) Temporal and spatial scales matter: Circannual habitat selection by bird communities in vineyards. PLOS ONE 12:1-28.

https://doi.org/10.1371/journal.pone.0170176

15. Henderson I, Vickery J, Carter N (2004) The use of winter bird crops by farmland birds in lowland England. Biol Conserv 118:21-32. https://doi.org/10.1016/j.biocon.2003.06.003

16. Hickling R, Roy DB, Hill JK et al (2006) The distributions of a wide range of taxonomic groups are expanding polewards. Glob Chang Biol 12:450-455. https://doi.org/10.1111/j.13652486.2006.01116.x

17. Hovick TJ, Allred BW, McGranahan DA et al (2016) Informing conservation by identifying range shift patterns across breeding habitats and migration strategies. Biodivers Conserv 25:345-356. https://doi.org/10.1007/s10531-016-1053-6

18. Koskimies P, Väisänen RA (1991) Monitoring bird populations: a manual of methods applied in Finland. Helsinki

19. Lehikoinen A, Jaatinen K, Vähätalo AV et al (2013) Rapid climate driven shifts in wintering distributions of three common waterbird species. Glob Chang Biol 19:2071-2081. https://doi.org/10.1111/gcb.12200

20. Lehikoinen A, Virkkala R (2016) North by North-West: Climate change and directions of density shifts in birds. Glob Chang Biol 22:1121-1129. https://doi.org/10.1111/gcb.13150

21. Lehikoinen P, Santangeli A, Jaatinen $\mathrm{K}$ et al (2019) Protected areas act as a buffer against detrimental effects of climate change-Evidence from large-scale, long-term abundance data. Glob Chang Biol 25:304-313. https://doi.org/10.1111/gcb.14461 
22. Lehikoinen A, Lindström Ã, Santangeli A et al (2021) Wintering bird communities are tracking climate change faster than breeding communities. J Anim Ecol 90:1085-1095.

https://doi.org/10.1111/1365-2656.13433

23. MacLean SA, Beissinger SR (2017) Species' traits as predictors of range shifts under contemporary climate change: A review and meta-analysis. Glob Chang Biol 23:4094-4105. https://doi.org/10.1111/gcb.13736

24. Mason SC, Palmer G, Fox R et al (2015) Geographical range margins of many taxonomic groups continue to shift polewards. Biol J Linn Soc 115:586-597. https://doi.org/10.1111/bij.12574

25. Masson-Delmotte V, Zhai P, Pörtner HO et al (2018) Global warming of 1.5 C. An IPCC Special Report on the impacts of global warming of 1.5

26. Pacifici M, Visconti P, Butchart SHM et al (2017) Species' traits influenced their response to recent climate change. Nat Clim Chang 7:205-208. https://doi.org/10.1038/nclimate3223

27. Patchett R, Finch T, Cresswell W (2018) Population consequences of migratory variability differ between flyways. Curr Biol 28:R340-R341. https://doi.org/10.1016/j.cub.2018.03.018

28. Pavón-Jordán D, Clausen $P$, Dagys $M$ et al (2019) Habitat- and species-mediated short- and long-term distributional changes in waterbird abundance linked to variation in European winter weather. Divers Distrib 25:225-239. https://doi.org/10.1111/ddi.12855

29. Platts PJ, Mason SC, Palmer G et al (2019) Habitat availability explains variation in climate-driven range shifts across multiple taxonomic groups. Sci Rep 9:15039. https://doi.org/10.1038/s41598019-51582-2

30. Pöyry J, Luoto M, Heikkinen RK et al (2009) Species traits explain recent range shifts of Finnish butterflies. Glob Chang Biol 15:732-743. https://doi.org/10.1111/j.1365-2486.2008.01789.x

31. R Core Team (2020) R: A language and environment for statistical computing. R Foundation for Statistical Computing, Vienna, Austria. URL https://www.R-project.org/

32. Rushing CS, Andrew Royle J, Ziolkowski DJ, Pardieck KL (2020) Migratory behavior and winter geography drive differential range shifts of eastern birds in response to recent climate change. Proc Natl Acad Sci U S A 117:12897-12903. https://doi.org/10.1073/pnas.2000299117

33. Ryding S, Klaassen M, Tattersall GJ et al (2021) Shape-shifting: changing animal morphologies as a response to climatic warming. Trends Ecol Evol 1-13. https://doi.org/10.1016/j.tree.2021.07.006

34. Santangeli A, Lehikoinen A (2017) Are winter and breeding bird communities able to track rapid climate change? Lessons from the high North. Divers Distrib 23:308-316. https://doi.org/10.1111/ddi.12529

35. Stephens PA, Mason LR, Green RE et al (2016) Consistent response of bird populations to climate change on two continents. Science (80-) 352:84-87. https://doi.org/10.1126/science.aac4858

36. Tayleur CM, Devictor V, Gaüzère P, Jonzén N, Smith HG, Lindström Ã (2016) Regional variation in climate change winners and losers highlights the rapid loss of cold-dwelling species. Divers Distrib 22:468-480. https://doi.org/10.1111/ddi.12412 
37. Thomas CD, Williamson M (2012) Extinction and climate change. Nature 482:E4-E5. https://doi.org/10.1038/nature10858

38. Van Doren BM, Conway GJ, Phillips RJ et al (2021) Human activity shapes the wintering ecology of a migratory bird. Glob Chang Biol 27:2715-2727. https://doi.org/10.1111/gcb.15597

39. Virkkala R, Rajasärkkä A (2011) Climate change affects populations of northern birds in boreal protected areas. Biol Lett 7:395-398. https://doi.org/10.1098/rsbl.2010.1052

40. Virkkala R, Lehikoinen A (2014) Patterns of climate-induced density shifts of species: Poleward shifts faster in northern boreal birds than in southern birds. Glob Chang Biol 20:2995-3003. https://doi.org/10.1111/gcb.12573

41. Williams CM, Henry HAL, Sinclair BJ (2015) Cold truths: how winter drives responses of terrestrial organisms to climate change. Biol Rev 90:214-235. https://doi.org/10.1111/brv.12105

\section{Figures}



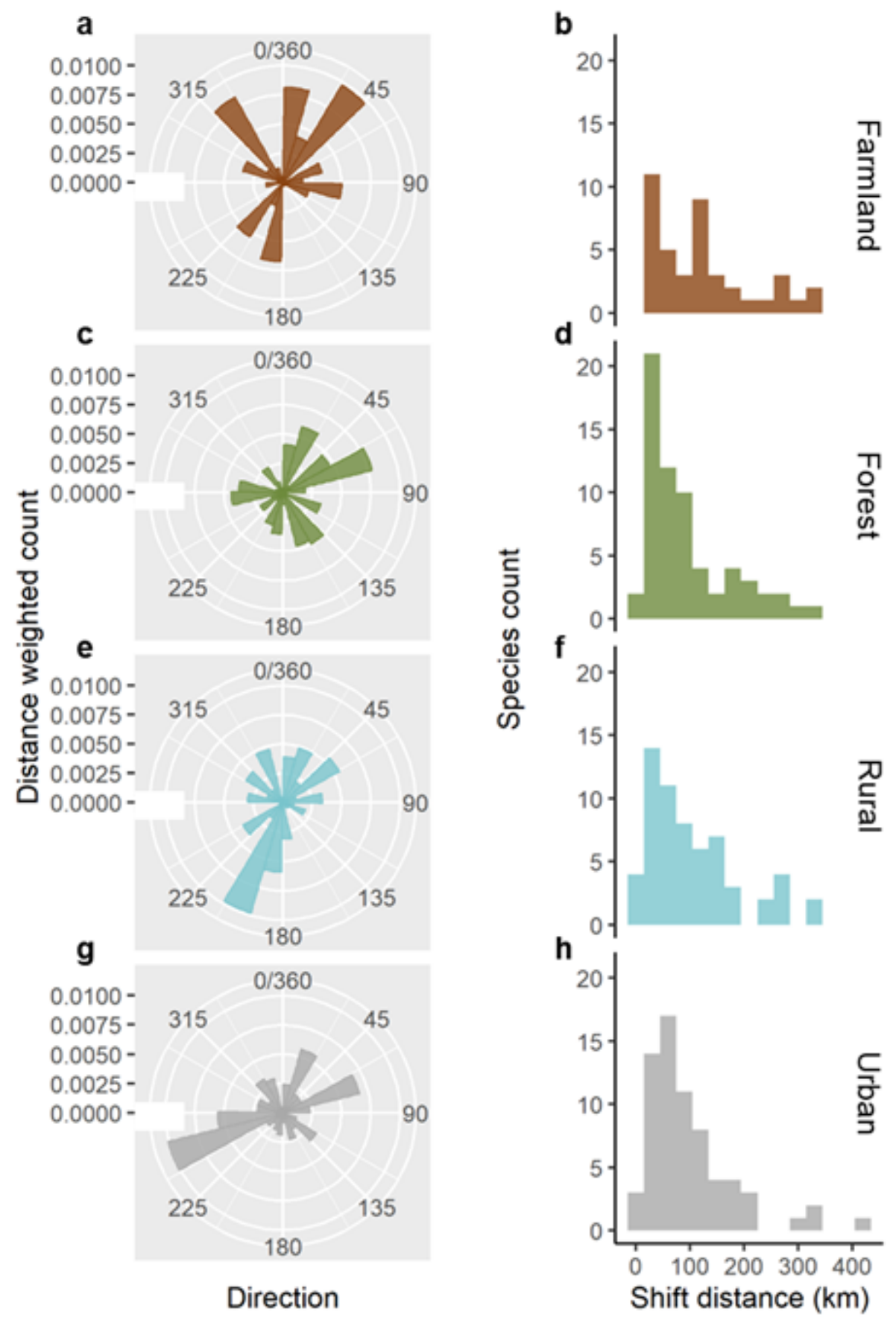

\section{Figure 1}

Habitat-specific circular histograms of the range shift direction patterns weighted by distance (left side) and histograms depicting the distance of latitudinal central gravity shifts, where the $y$-axes of histograms show the distance-weighted counts (right side).

\section{Figure 2}


Predicted effects on northward shift direction in centre of gravity per four habitat types based on the additive model $(\mathrm{m} 4)$. Colored points show predicted means per habitat type with $95 \%$ confidence intervals (bars), while grey points represent the raw data. Effect plot of snow period 2 is shown in Fig. S8 in ESM. Higher northward values indicate northward shifts $(+1)$, lower values southward shifts $(-1)$.

\section{Figure 3}

Predicted effects on shift distances of northern range margins in relation to snow cover in period 2 in a) farmland, b) forest, c) rural and d) urban habitats. Regression lines show model estimates, shaded areas $95 \%$ confidence intervals and points the raw data. Note that species-habitat combinations where the northern range was higher than $66.85^{\circ} \mathrm{N}$ latitude were excluded $(\mathrm{N}=4$ species including 54 grid observations).

\section{Figure 4}

Predicted effects of relative densities (low values = generalists; high values = specialists) on northward shift direction. Regression lines show model estimates, shaded areas 95\% confidence intervals and grey points the raw data. Higher northward values indicate northward shifts $(+1)$, lower values southward shifts $(-1)$.

\section{Supplementary Files}

This is a list of supplementary files associated with this preprint. Click to download.

- Boscoetal.2021ESMOec.docx 